\title{
Interdisciplinary Collaboration: Cognitive Behavioral Interventions in Special Education and School Psychology
}

\author{
Tachelle Banks ${ }^{1}$, Garry Squires ${ }^{2}$, Karla Anhalt ${ }^{3}$ \\ ${ }^{1}$ Special Education, Cleveland State University, Cleveland, USA \\ ${ }^{2}$ Educational Psychology, University of Manchester, Manchester, UK \\ ${ }^{3}$ School Psychology, Kent State University, Kent, USA \\ Email: t.i.banks@csuohio.edu
}

Received 23 April 2014; revised 20 May 2014; accepted 31 May 2014

Copyright (C) 2014 by authors and Scientific Research Publishing Inc.

This work is licensed under the Creative Commons Attribution International License (CC BY). http://creativecommons.org/licenses/by/4.0/

(c) (i) Open Access

\begin{abstract}
Cognitive behavioral interventions (CBIs) attempt to affect behavior change by teaching relevant tasks that are based around strategies to correct cognitive distortions through the application of logic and the search for evidence. Goals are clearly specified; decisions are made on how to best meet specified goals and how to measure progress toward goals to provide feedback. The intervention is task-oriented and focused on problem-solving. This article provides a brief review of the theoretical tenets of CBIs and use with children and adolescents. A review of the literature describes the efficacy and practical implementation of CBIs in school settings. An interdisciplinary collaborative framework is discussed to better support the implementation of school-based mental health programming in schools.
\end{abstract}

\section{Keywords}

Cognitive Behavioral Interventions, School Psychologists, Children's Mental Health, Special Education, Educational Settings

\section{Introduction}

Children's mental health is a growing concern in many countries, with demand for specialist services outstripping availability. For example, as many as $10 \%$ of children in UK are considered to have a mental health problem (Bird, 2006; Department for Children, Schools and Families, \& Department of Health, 2009; Layard, 2008; National Institute for Health and Clinical Excellence, 2008) that, unless resolved, will remain a problem into

How to cite this paper: Banks, T., Squires, G., \& Anhalt, K. (2014). Interdisciplinary Collaboration: Cognitive Behavioral Interventions in Special Education and School Psychology. Creative Education, 5, 758-768.

http://dx.doi.org/10.4236/ce.2014.510089 
adulthood and reduce the capacity for employed work as well as contributions made to the economy (Layard, 2005; Layard, Clark, Knapp, \& Mayraz, 2007). There has been a more general recognition of the need for professionals to intervene more effectively in school settings to promote early identification and intervention (for example, see Aggett, Boyd, \& Fletcher, 2006; Department of Health, 2004; Langley, Nadeem, Kataoka, Stein, \& Jaycox, 2010; Pettitt, 2003). There have been several attempts to improve the role of schools and school-based programs to address these concerns, such as the Social and Emotional Aspects of Learning (SEAL) program in the UK (Department for Education and Skills, 2007), the Friends for Life program in Australia (Barrett, 1996), or the Promoting Alternative Thinking Strategies curriculum (PATHS) in the US (Kusche \& Greenberg, 1993). These programs emphasize on placing educators and school psychologists on the front line of service delivery. School psychologists are particularly well placed in delivering individual and small group programs and have extensive training in psychology to inform their therapeutic practice (Squires, 2010; Squires \& Dunsmuir, 2011). Many of these approaches have a basis in cognitive behavioral interventions (CBIs).

In the US, the Report of the Surgeon General's Conference on Children's Mental Health noted the public crisis in meeting the mental health needs of youth (US Public Health Service, 2000). In addition, the academic and social challenges facing public schools are enormous. For example, the pressure to meet the demands of the current high-stakes testing environment and reach adequate yearly progress (AYP) goals has arguably never been greater (Luna \& Turner, 2001; Sanders, 2003). The energy devoted to academics has supplanted the little time spent on the social, behavioral, and emotional needs of students. The need to create classroom environments that are safe for all students persists. Despite the need for services, only a fraction of children and adolescents receive adequate mental health services (US Public Health Service, 2000). Abelson and Taylor (2000) addressed this problem when they wrote that many students are not receiving the mental health programs that they desperately need:

“Too many schools can’t meet basic needs. Primary prevention is only a dream. The simple fact is that education support activity is marginalized at most schools, and thus the positive impact such activity could have for the entire school is sharply curtailed" (p. 50).

Given barriers related to availability and accessibility of mental health services, schools have been identified as natural contexts for the provision of such supports to children (Doll \& Cummings, 2008). In preparing children to deal with life in an increasingly complex society, it is important that schools devote attention to well-organized and theoretically-sound programs employing a preventive approach to mental health. Preventive mental health curricula should focus upon developing in children and youth an awareness of self (in general), feelings, self in relation to others, and decision-making and problem-solving skills (Trip, Vernon, \& McMahon, 2007). Preventive mental health curriculum as defined in this context regards mental health promotion as an educational intervention that can be delivered in classrooms. In this sense, the educational aspect of a mental health promotion curriculum attempts to teach students how to help themselves by providing a structured method of developing emotional and social competencies. Such a mental health curriculum can be delivered in classroom settings to address and remediate the socio-emotional needs of students with and without disabilities. School-based mental health programming can be integrated with an academic curriculum and designed both to address the emotional and behavioral problems of students and, more importantly, give them the tools necessary to be able to prevent and manage them (Banks, 2011, 2012; Banks \& Zionts, 2008, 2009; Zionts, Banks, \& Killu, 2013). This article provides a brief review of the theoretical tenets of CBIs and use with children and adolescents. A review of the literature describes the practical implementation and efficacy of CBIs in school settings. An interdisciplinary collaborative framework is discussed to better support the implementation of school-based mental health programming in schools.

\section{Cognitive Behavior Interventions}

In CBIs, the inter-relationship of thoughts, feelings, and behaviors is central to understanding how a person reacts in any particular social situation. Fundamental to these approaches is the premise that our understanding of the world is constructed and open to change (Kelly, 1955). It is likely that different people experiencing the same set of events will construct what is happening in different ways, leading to different interpretations, emotional responses, and behavioral reactions.

Events that most people would see as normal and non-threatening take on a different and more sinister mean- 
ing for other people. Cognitive theories that attempt to explain this different interpretation have been identified as either suggesting cognitive distortions (Lochman \& Dodge, 1998) or suggesting cognitive deficits (Asarnow \& Callan, 1985). Kendall (1993) described the differences between cognitive distortions and cognitive deficiencies: cognitive deficiency is an absence of thinking about a certain topic where analysis would be helpful, while cognitive distortion exaggerates or reduces the importance of key information. For example, a child may see the world as a hostile place when other pupils are seen as better or smarter, while he sees himself as worthless and unworthy of teacher attention. Such cognitive distortions and unhelpful thinking lead to poorly adjusted moods, such as depression, anxiety, low self-esteem, or anger. These moods in turn contribute to dysfunctional behaviors such as school avoidance, low levels of performance, reluctance to try new things, acting out, or being verbally abusive.

CBIs attempt to change dysfunctional behavior by addressing the cognitive processes that bring about a change in psychopathology (Silverman \& DiGiuseppe, 2001). This is referred to as cognitive restructuring (Beck \& Emery, 1979; Beck, Emery, \& Greenberg, 1985; Beck, Freeman, \& Associates, 1990; Beck, Rush, Shaw, \& Emery, 1979). CBIs work by using evidence to correct distortions, problem-solving techniques to manage situations, behavioral experiments to challenge beliefs, behavioral techniques to moderate feelings, and self-monitoring techniques to increase self-awareness of many thought processes that are seemingly automatic.

The role of automatic thinking is important with many cognitive theories drawing on schema theory (Etscheidt, 1991; Gonzalez et al., 2004; Silverman \& DiGiuseppe, 2001). In schema theory, many routine cognitive processes are reduced to internalized automatic sequences that, once activated, continue to run to an end point without the need for conscious attention; most of the time, this is helpful in that it reduces cognitive load. For example, a learning driver requires a lot of thought and attention to each action, whereas an experienced driver can negotiate many obstacles on a journey without much conscious effort. In the same way, cognitive distortions are associated with dysfunctional schemata and automatic thinking (Kihlstrom, 1987). Viewed in this way, cognitive distortions are involuntary perceptions and thoughts that are activated through habitual practice and reinforcement, based on past experiences that connect old information with new information (Kihlstrom, 1987; Robins \& Hayes, 1993), and maintain established ways of responding. These processes are automatic in the sense that thinking patterns are unattended, not conscious, or occur without regard to how conclusions are derived. The perceived intentions of other individuals or situations are not innate, but learned and reinforced by routine practice (Kihlstrom, 1987; Robins \& Hayes, 1993).

The appraisal of the situation happens very quickly and we are often not aware of the contributing thoughts. Such thoughts are referred to as automatic thoughts and lead to the activation of a whole range of responses that make up the schema (Figure 1). For example, Jane is asked to read out loud in class. An automatic thought flashes through her head so quickly that she is unaware of it: "I'm useless at reading." Her physiological system becomes activated with an increase in heart rate and release of adrenaline-the fight or flight hormone. Cognitively, she thinks, "I'll probably make mistakes and the other kids will laugh." She becomes motivated to avoid

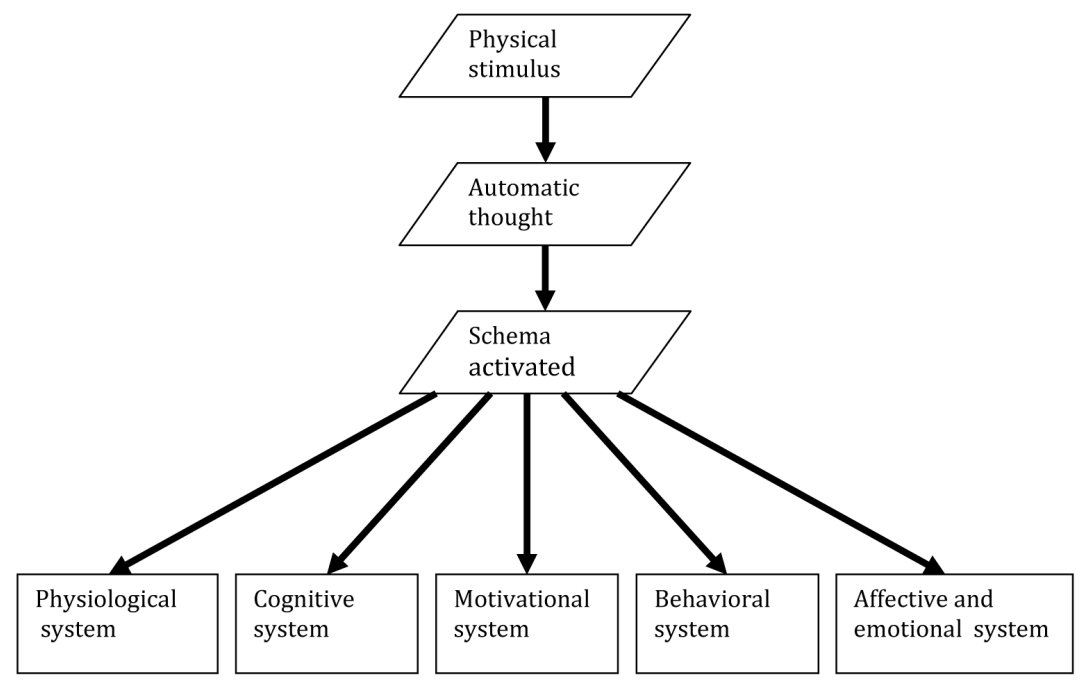

Figure 1. Schema activation adapted from Squires (2002). 
the situation, “If I get sent out, I won’t have to do this.” Emotional responses might include feeling ashamed or even angry that the teacher is putting her through this ordeal. She may even think that the teacher hates herwhy else would she make her feel like this? Further evaluations of the situation might lead her to notice David smiling. Another automatic thought enters into play, "He's laughing at me;" this leads to the behavior of verbal or physical abuse of the child who smiled. This is the behavior the teacher sees that sends Jane out of the room.

\section{Educational Applications of CBIs}

CBIs consciously recognize the wide individual differences observed in the way students in school (and elsewhere) react to the same event (DiGiuseppe, 1990). Preventive mental health curricula should focus upon developing in children and youth an awareness of self (in general), feelings, self in relation to others, and decision-making and problem-solving skills to better prepare them to deal with life in an increasingly complex society. It is important that schools devote attention to well-organized and theoretically-sound programs employing a preventive approach to mental health programming that is cognizant of cultural and linguistic differences and designed to meet the needs of all children and youth.

CBIs encompass a variety of instructional strategies and have been utilized across diverse populations; therefore, it may be more difficult to ascertain their effectiveness, as there is no prescribed method of CBI. The efficacy of CBI strategies is directly related to the specific characteristics, traits, and attributes associated with each group (Morris, 1993). Many programs utilize combinations of instructional strategies that contribute to the lack of clarity regarding specific treatment effects. CBI researchers have discussed the associated difficulties in determining the efficacy of CBIs, due to variations in training approaches. Components of CBI training include, but are not limited to, self-instruction, self-control, role-play, modeling, coaching, problem-solving, and response-cost procedures (Ager \& Cole, 1991; Etscheidt, 1991; Kazdin, 1991; Kendall, Reber, McLeer, Epps, \& Ronan, 1990). The articles reviewed confirm the precedent for implementing preventive mental health curriculum in classroom settings and discuss affective programming that recognizes the interrelationship between thinking, feelings, and behavior, and includes an educational component that provides a strategy to manage extreme emotions.

An important behavioral problem of childhood is impulsivity, which is usually treated behaviorally or cognitively. Impulsivity has been found to cause antisocial behaviors, such as aggression, attention deficit hyperactivity disorder (ADHD), and peer problems. Baer and Nietzel (1991) examined the literature base for cognitive and behavioral treatment of impulsivity in children. Studies were included if: 1) subjects were less than 18 years old, 2) the behavior of interest was described as impulsiveness, 3) one or more measures of impulsivity were used as an outcome measure, 4) they compared at least one cognitive and/or behavioral treatment group with a placebo group, and 5) they were published in English language journals. The results showed that untreated groups improved in Matching Familiar Figures (MFF) test error scores with repeated testing, but treated groups displayed larger improvements. Overall, impulsivity interventions allowed for improvements.

DuPaul and Eckert (1997) examined the effects of school-based interventions for students with ADHD. The researchers found that interventions for ADHD have increased gradually in frequency in the 24-year period covered by the meta-analysis. Most of the studies determined the effects of CBIs and contingency management. Interventions in special education classrooms had significantly greater behavioral effects than interventions in general education classrooms. Contingency management and academic intervention were significantly more effective than CBIs. Public school interventions were significantly more effective than non-public school interventions. Overall, this meta-analysis showed that school-based interventions for students with ADHD allowed for significant behavioral effects.

Primary prevention is designed to reduce the future incidence of adjustment problems in normal populations, including mental health promotion. Durlak and Wells (1997) assessed the impact and outcomes of primary prevention programs. In this meta-analysis, a total of 177 interventions were reviewed, 150 from published reports and 27 from unpublished doctoral dissertations. The studies were coded on 51 variables within seven major categories, which included 1) basic identifying data, 2) methodological features, 3) effect size calculations, 4) subject characteristics, 5) change agents characteristics, 6) intervention characteristics, and 7) outcome measures. The mean age of participants was 9.3 years. Almost half of the studies collected follow-up information, although the time for follow-up varied considerably. Most of the interventions took place in a preschool, primary, or secondary school. Most of the interventions were person-centered. Person-centered programs were divided into affective education or interpersonal problem-solving. Students who were taught behavioral strategies and had ef- 
fective teacher-student relationships were less likely to be aggressive and more likely to achieve in school. Durlak and Wells found that problem-solving programs and affective education worked best in young children as compared to older children in person-centered programs. The primary prevention model was strongly supported and interventions produced significant improvements in multiple domains of adjustment; these gains did not weaken over time.

Secondary interventions are designed to identify early risk factors and intervene before the development of disorders. These interventions are most likely to occur when mental health problems have worsened. Durlak and Wells (1998) identified variables that influenced outcomes for children and adolescents. A total of 130 interventions were used in this meta-analysis. A majority of the studies were school-based and in an elementary school. Each study was coded based on the following categories: 1) basic identifying data, 2) design features, 3) target population characteristics, 4) therapist characteristics, 5) treatment characteristics, and 6) outcome measures. Studies were also coded for seriousness and type of presenting problems for children, including poor peer relations; poor academic performance; and internalizing, externalizing, and mixed adjustment problems. Both behavioral and cognitive-behavior treatment created significantly higher overall mean effects than non-behavioral treatment. However, cognitive-behavior treatment was significantly more effective than behavioral treatment. In terms of practical significance, participants in treatment groups had significantly better outcomes than participants in control groups for both behavioral and cognitive-behavior treatment.

Robinson, Smith, and Miller (2002) examined the effects of CBI on inappropriate anger behavioral responses by middle school students. The students were all males in the sixth, seventh, and eighth grades identified as having emotional and/or behavioral problems. The treatment included 50-minute sessions over five weeks, based on the Anger Control Curriculum (ACC). The authors added a few extra elements into ACC: 1) lessons on understanding and handling anger, 2) lessons on effective communication, 3) introduction to relaxation techniques, 4) presentation of problem-solving skills, 5) modeling the intervention steps, and 6) practice paired with performance feedback from students and teachers. The ACC uses behavioral-based interventions in order to teach the cognitive processes involved with problem-solving. The problem situations were based on students' real life problems. The results showed that after exposure to the ACC, the treatment group experienced lower levels of anger than the control group. Anecdotal evidence supported the results. The teachers and students were favorably responsive to the ACC lessons and activities. Teachers said that student behavior improved as a result of ACC, as students took more time to think before acting. Students were a little critical of the ACC, but still stated that it helped them deal with their anger in better ways instead of just going to an adult or fighting. Some students complained that the lessons were too long and became boring. Teachers believed that the lessons were not as effective as they could have been and that the students probably would not generalize the skills learned to other settings.

Squires \& Caddick (2012) examined the effectiveness of a school-based CBI program. The participants in this study were students in a high school setting who were identified as having externalizing behavioral challenges. They were ages 12 and 13, with more boys in the study. The teachers as well as the participant students rated the students' behavioral problems using the checklists from the Behaviour Assessment System for Children (BASC2). Based on their behavioral problems, students were matched in pairs, with one student being in the treatment group and the other student being in the control group. The intervention was one hour a week for eight weeks. The intervention focused on the following: 1) increasing awareness of feelings, thoughts, and inner speech that linked to behavior; 2) acknowledging the usual thoughts and responses; 3) deciding upon alternative thoughts and responses in comparison to the usual thoughts; 4) understanding the difference between beliefs and facts; 5) training for behavioral skills and coping strategies; 6) creating homework exercises to practice the covered strategies; and 7) using group problem-solving skills. The control group only received the regular support that the school gave these students.

The students in the treatment group reported greater improvements in behavior as well as management of behavior than those in the control group. The control group believed that their behavior had worsened. However, teachers believed that both groups experienced improvement in their behavior, which was unexpected to the authors. They suspected that since the teachers did not know which students were in which group, the teachers believed that all the students had room for improvement. The authors believed that the targeted intervention would affect the whole class and even the entire school because it 1 ) developed the capacity within the system to respond better to the behavior of children using cognitive behavioral therapy (CBT) models, 2) reduced stressors for teachers, and 3) allowed for the treatment group to act as models for the control group. 
Rational Emotive Behavior Therapy (REBT) is considered a comprehensive intervention that incorporates cognitive restructuring with emotions and behavioral applications. The goals of REBT in the treatment of school-aged populations are similar to those in adult treatment, although the means vary depending on the cognitive-developmental status and intelligence level of the student (Bernard, 1990). REBT is aimed at bringing about a decrease in the intensity of extreme, negative emotions of students. REBT is designed to help students solve particular problems, as well as reduce extreme levels of anger, anxiety, and depression that may prevent students from thinking clearly so that they can problem-solve (Bernard, 1990). REBT principles have been used with children and adolescents and found to be an effective intervention (Ellis \& Wilde, 2002). REBT has been found to be successful in reducing anxiety (Rosenbaum, McMurray, \& Campbell, 1991), increasing frustration tolerance, improving academic performance (Sapp, 1996; Shannon \& Allen, 1998), reducing depression (Wilde, 1994), improving social skills (Flanagan, Povall, Dellino, \& Byrne, 1998), and improving self-concept and coping capabilities (LaConte, Shaw, \& Dunn, 1993; Morris, 1993).

Modification of emotional problems is accomplished by changing the student's perceptions and evaluations (DiGiuseppe, 1990; Knaus, 2001; Vernon, 1989a). Students are asked to challenge their irrational thinking by providing evidence to support their (faulty) conclusions (Ellis \& Wilde, 2002). Changing the faulty assumptions under which the student is operating will decrease the intensity of his emotions (DiGiuseppe \& Bernard, 1990; Dryden, DiGiuseppe, \& Neenan, 2003; Ellis, 1991; Ellis \& Wilde, 2002). An educational curriculum based on the principles of REBT provides a mental health prevention program that is particularly suited to a schooloriented approach (Vernon, 1989b; Zionts, Banks, \& Killu, 2013). This programming teaches problem-solving strategies that have been adapted from the principles of REBT (Knaus, 2001).

Banks (2008) studied the practical implementation of REBT in an alternative urban educational setting. The purpose of the study was to determine if students identified as having significant emotional disorders (ED) could learn the content of REBT. The researcher implemented an instructional sequence as a pullout program in a day treatment setting that serves students with severe emotional and behavioral disorders (EBD). Fourteen students between the ages of 11 - 14 were selected to participate in this study. The students were part of a convenience sample of intact classrooms with seven students per classroom. The REBT group met twice weekly for twenty 30-minute sessions across a 24-week period. The researcher led activities and group discussions with the school psychologists interested in observing REBT techniques. The results from the study indicated that there were no significant differences between students who participated in REBT sessions and students who did not participate in REBT sessions, as indicated by scores on the IDEA Inventory (Kassinove, Crisci, \& Tiegerman, 1977).

Despite the lack of statistically significant change between groups, students who participated in the sessions clearly learned the model as indicated by their ability to use the model during group discussions. Students were able to identify critical components of the model and apply the skills learned to talk through events that interfered with their ability to be successful in the educational environment. Among the critical findings were that the classroom teacher needs to play a more integral role in the instruction of REBT in an effort to promote curriculum integration. That way, students are able to practice the strategy every day, throughout the day, in order to foster automaticity and ownership of the strategy, thus increasing the chances of generalization of skills. The presence of a consultant, even though she was fairly well known to the students and the staff, did not allow for the consistency needed to reinforce the skill learned. Each session that follows contains the stated purpose and objective(s) for each lesson and suggested learning activities. It may take several teaching sessions to achieve mastery of the skills. This means that the number of sessions depends on the individual student's learning abilities and time devoted to teaching rational skills.

The review of the literature confirms the effectiveness of CBIs with children and youth. Still, challenges associated with fidelity of implementation and generalization of skills support the notion of development of a collaborative framework that would better address factors that can adversely impact implementation of preventative mental health curriculum in classroom settings. Specifically, 1) the development of educational, affective lessons that are individualized for a particular context (Robinson, Smith, \& Miller, 2002); 2) greater curriculum integration to foster automaticity, ownership of the strategy and generalization (Banks, 2008); and 3) developing the capacity within schools to respond better to the needs of children and teachers (Squires \& Caddick, 2012). There is paucity for a research-based collaborative framework that would better support efficacy and fidelity of CBIs in schools and the implementation of school-based mental health programs. The following section proposes to encourage an interdisciplinary collaborative framework model to better address emotional and behavioral needs of students. 


\section{Interdisciplinary Collaborative Framework: Practical Considerations}

The field of behavior disorders is contemplating a strategic shift to better meet the needs of students who are identified as having EBD. The shift is based on the need to focus on students with externalizing behaviors as well as internalizing behaviors (Peck et al., 2012). There is a discrepancy and subsequent lack of services for students with internalizing disorders, such as depression and anxiety. The shift involves more than just a change of name that will emphasize emotional as well as behavioral disorders; it looks to promote mental health programming in schools in collaboration with related professions (Peck et al., 2012). Forness (in press) highlighted the need to focus on comorbidity and collaboration as future behavior disorder endeavors. In his review of considering changes in the field of behavior disorders, he discussed the importance of interdisciplinary collaboration to best address the mental health needs of students identified as having EBD.

School counselors and school psychologists are key school-based mental health professionals who can facilitate the delivery of mental health curriculum and intervention in school settings. They play a critical role in providing support to targeted children, especially interventions (Squires \& Caddick, 2012). School psychologists and school counselors are highly skilled professionals and are capable of applying their skills in a variety of settings. School psychologists and school counselors have expertise in psychological and therapeutic interventions. While they are better prepared to deliver socio-emotional curricula, ongoing access to the classroom can be limited, which can adversely impact treatment integrity (Pugh, 2010). Teachers implement the academic curriculum in classrooms, and they are equally positioned to deliver universal prevention-based socio-emotional curriculum in schools when their professional development has incorporated this domain (Miller et al., 2010; Squires, 2010). Moreover, schools are a natural environment for students; teachers are therefore in a unique position to assess the socio-emotional needs of students in classrooms more frequently. Since teachers know the academic and socio-emotional needs of their students, they can formally and informally assess performance and change.

The identified strengths of the professions may inform an interdisciplinary model of collaboration that will support implementing preventive mental health curriculum in educational settings. For example, school psychologists and school counselors possess the knowledge and skills to provide training and support to teachers and related professionals to deliver socio-emotional interventions in a manner that is conducive to fidelity and treatment integrity. Counselors can deliver therapeutic services in the forms of mediation and coaching to students as well as provide intervention support for teachers. Case in point, a school psychologist can train teachers in theoretical underpinnings of REBT and support the evidence-based implementation of REBT tools in classrooms. Partnerships must be created between school-based mental health professionals and teachers to implement socio-emotional interventions in schools with fidelity (Pugh, 2010). School psychologists and school counselors can assist with bridging the gap between research and practice in an applied context by collaborating with teachers to better support the mental health needs of students. In addition, professionals working in collaboration would support reliability of implementation. Increased trustworthiness in CBI research findings would legitimize interventions and positively affect validity.

Perhaps future researchers will consider an interdisciplinary collaborative model that would better support the use of mixed methodology, including multiple-group designs and qualitative inquiry, where the REBT strategies are delivered by the teacher who is trained by school psychologists, ensuring curriculum integration. Data can be collected in a more predictable and consistent fashion. For students who require more intensive mental health interventions, school psychologists and/or school counselors can conduct multiple small groups using REBT (including fidelity of treatment measures that are disseminated and collected by teachers) or qualitative design, which allows for closer inspection of contextual variables that may influence the outcomes of the interventions (Denzin \& Lincoln, 2000). The conflict lies in practice and research, and collaboration amongst professionals may serve as the best option to address divergence.

\section{Conclusion}

The consequences of not preparing students in both the academic and social-emotional domains affect every aspect of the school and community culture. One cannot demand skill performance without first teaching the skill. Punishing and excluding students who do not possess self-control only exacerbates their problems. CBIs attempt to affect behavior change by teaching relevant tasks that are based around strategies to correct cognitive distortions through the application of logic and the search for evidence (Etscheidt, 1991; Squires, 2002). The interventions are task-oriented and focused on problem-solving. The review of the literature illustrates the efficacy of 
CBIs and how such strategies can be taught to students in school settings. Mental health promotion programs should be an integral part of school curriculum using a collaborative model, including school counselors, school psychologists, and teachers to ensure intervention fidelity and treatment integrity.

\section{References}

Abelson, H. S., \& Taylor, L. (2000). Shaping the Future of Mental Health in Schools. Psychology in the Schools, 37, 49-60. http://dx.doi.org/10.1002/(SICI)1520-6807(200001)37:1<49::AID-PITS6>3.0.CO;2-0

Ager, C. L., \& Cole, C. L. (1991). A Review of Cognitive-Behavioral Interventions for Children and Adolescents with Behavioral Disorders. Behavioral Disorders, 16, 276-287.

Aggett, P., Boyd, E., \& Fletcher, J. (2006). Developing a Tier 1 CAMHS Foundation Course: Report on a 4-Year Initiative. Clinical Child Psychology and Psychiatry, 11, 319-333. http://dx.doi.org/10.1177/1359104506064981

Asarnow, J. R., \& Callan, J. W. (1985). Boys with Peer Adjustment Problems: Social Cognitive Processes. Journal of Consulting and Clinical Psychology, 53, 80-87. http://dx.doi.org/10.1037/0022-006X.53.1.80

Baer, R. A., \& Nietzel, M. T. (1991). Cognitive and Behavioral Treatment of Impulsivity in Children: A Meta-Analytic Review of the Outcome Literature. Journal of Clinical Child Psychology, 20, 400-412. http://dx.doi.org/10.1207/s15374424jccp2004 9

Banks, T. (2008). Teaching a Cognitive Behavioral Strategy to Manage Emotion: Rational Emotive Behavior Therapy in an Urban Education Setting. VDM Verlag Dr. Muller Aktiengesellschaft \& Co. KG.

Banks, T. (2011). Helping Students Manage Feelings: REBT as a Mental Health Educational Curriculum. Educational Psychology in Practice, 27, 383-394. http://dx.doi.org/10.1080/02667363.2011.624303

Banks, T. (2012). Rational Emotive Behavior Therapy with Diverse Student Populations: Meeting the Mental Health Needs of All Students. Multicultural Learning and Teaching, 7. http://dx.doi.org/10.1515/2161-2412.1154

Banks, T., \& Zionts, P. (2008). REBT Used with Children and Adolescents Who Have Emotional and Behavioral Disorders in Classroom Settings: A Review of the Literature. Journal of Rational Emotive and Cognitive Behavior Therapy, 27, 5165. http://dx.doi.org/10.1007/s10942-008-0081-x

Banks, T., \& Zionts, P. (2009). Teaching a Cognitive Behavioral Strategy to Manage Emotions: REBT in an Educational Setting. Intervention in School \& Clinic, 44, 307-313. http://dx.doi.org/10.1177/1053451208330893

Barrett, P. (1996). FRIENDS for Life. Bowen Hills: Australian Academic Press.

Beck, A. T., \& Emery, G. (1979). Cognitive Therapy of Anxiety and Phobic Disorders. Philadelphia: Center for Cognitive Therapy.

Beck, A. T., Emery, G., \& Greenberg, R. (1985). Anxiety Disorders and Phobias: A Cognitive Perspective. New York: Basic Books Inc.

Beck, A. T., Freeman, E., \& Associates (1990). Cognitive Therapy of Personality Disorders. London: The Guilford Press.

Beck, A. T., Rush, A., Shaw, B., \& Emery, G. (1979). Cognitive Therapy of Depression. New York: The Guilford Press.

Bernard, M. E. (1990). Rational-Emotive Therapy with Children and Adolescents: Treatment Strategies. School Psychology Review, 19, 294-303.

Bird, A. (2006). We Need to Talk: The Case for Psychological Therapy on the NHS. London: The Mental Health Foundation.

Denzin, N. K., \& Lincoln, Y. S. (2000). Handbook of Qualitative Research. Thousand Oaks, CA: Sage Publications.

Department for Children, Schools and Families, \& Department of Health (2009). Healthy Lives, Brighter Futures. The Strategy for Children and Young People's Health. London: Central Office of Information for the Department of Health and the Department for Children, Schools and Families.

Department for Education and Skills (2007). Social and Emotional Aspects of Learning... Improving Behaviour... Improving Learning.

http://webarchive.nationalarchives.gov.uk/20081117141643/standards.dfes.gov.uk/primary/publications/band a/seal/

Department of Health (2004). CAMHS Standard, National Service Framework for Children, Young People and Maternity Services: The Mental Health and Psychological Well-Being of Children and Young People. London: DoH Publications.

DiGiuseppe, R. (1990). Rational-Emotive Assessment of School-Aged Children. School Psychology Review, 19, $287-293$.

DiGiuseppe, R., \& Bernard, M. E. (1990). The Application of Rational-Emotive Theory and Therapy to School-Aged Children. School Psychology Review, 19, 268-287.

Doll, B., \& Cummings, J. A. (2008). Best Practices in Population-Based School Mental Health Services. In A. Thomas, \& J. Grimes (Eds.), Best Practices in School Psychology V (pp. 1333-1347). Bethesda, MD: National Association of School 
Psychologists.

Dryden, W., DiGiuseppe, R., \& Neenan, M. (2003). A Primer on Rational Emotive Behavior Therapy (2nd ed.). Champaign, IL: Research Press.

DuPaul, G. J., \& Eckert, T. L. (1997). The Effects of School-Based Interventions for Attention Deficit Hyperactivity Disorder: A Meta-Analysis. School Psychology Review, 26, 5-27.

Durlak, J. A., \& Wells, A. M. (1997). Primary Prevention Mental Health Programs for Children and Adolescents: A MetaAnalytic Review. American Journal of Community Psychology, 25, 115-152. http://dx.doi.org/10.1023/A:1024654026646

Durlak, J. A., \& Wells, A. M. (1998). Evaluation of Indicated Preventive Intervention (Secondary Prevention) Mental Health Programs for Children and Adolescents. American Journal of Community Psychology, 26, 775-802. http://dx.doi.org/10.1023/A:1022162015815

Ellis, A. (1991). The ABC's of RET. The Humanist, 51, 19-49.

Ellis, A., \& Wilde, J. (2002). Case Studies in Rational Emotive Behavior Therapy with Children and Adolescents. Upper Saddle River, NJ: Prentice Hall.

Etscheidt, S. (1991). Reducing Aggressive Behavior and Increasing Self-Control: A Cognitive-Behavioral Training Program for Behaviorally Disordered Adolescents. Behavioral Disorders, 16, 107-115.

Flanagan, R., Povall, L., Dellino, M., \& Bryne, L. (1998). A Comparison of Problem Solving with and without Rational Emotive Behavior Therapy to Improve Children's Social Skills. Journal of Rational-Emotive \& Cognitive-Behavior Therapy, 16, 125-134. http://dx.doi.org/10.1023/A:1024986327879

Forness, S. (in Press). Reflections on the Future of CCBD: Behavioral Disorders. Book Submitted for Publication.

Gonzalez, J. E., Nelson, J. R., Gutkin, T. B., Saunders, A., Galloway, A., \& Shwery, C. S. (2004). Rational Emotive Therapy with Children and Adolescents: A Meta-Analysis. Journal of Emotional and Behavioral Disorders, 12, 222-235. http://dx.doi.org/10.1177/10634266040120040301

Kassinove, H., Crisci, R., \& Tiegerman, S. (1977). Developmental Trends in Rational Thinking: Implications for RationalEmotive, School Mental Health Programs. Journal of Community Psychology, 5, 266-274. http://dx.doi.org/10.1002/1520-6629(197707)5:3<266::AID-JCOP2290050312>3.0.CO;2-3

Kazdin, A. E. (1991). Effectiveness of Psychotherapy with Children and Adolescents. Journal of Consulting and Clinical Psychology, 59, 785-798. http://dx.doi.org/10.1037/0022-006X.59.6.785

Kelly, G. A. (1955). The Psychology of Personal Constructs. New York: Norton.

Kendall, P. C. (1993). Cognitive-Behavioral Therapies with Youth: Guiding Theory, Current Status, and Emerging Developments. Journal of Consulting and Clinical Psychology, 61, 235-247. http://dx.doi.org/10.1037/0022-006X.61.2.235

Kendall, P. C., Reber, M., McLeer, S., Epps, J., \& Ronan, K. R. (1990). Cognitive-Behavioral Treatment of Conduct-Disordered Children. Cognitive Therapy and Research, 14, 279-297. http://dx.doi.org/10.1007/BF01183997

Kihlstrom, J. F. (1987). The Cognitive Unconscious. Science, 237, 1445-1452. http://dx.doi.org/10.1126/science.3629249

Knaus, W. (2001). Rational Emotive Education. Theory in Practice, 16, 251-255. http://dx.doi.org/10.1080/00405847709542709

Kusche, C. A., \& Greenberg, M. T. (1993). The PATHS (Promoting Alternative Thinking Strategies) Curriculum. Deerfield, MA: Channing-Bete Company.

LaConte, M. A., Shaw, D., \& Dunn, I. (1993). The Effects of a Rational-Emotive Education Program for High-Risk Middle School Students. Psychology in the Schools, 30, 274-281. http://dx.doi.org/10.1002/1520-6807(199307)30:3<274::AID-PITS2310300310>3.0.CO;2-R

Langley, A. K., Nadeem, E., Kataoka, S. H., Stein, B. D., \& Jaycox, L. H. (2010). Evidence Based Mental Health Programs in Schools: Barriers and Facilitators of Successful Implementation. School Mental Health, 2, 105-113.

http://dx.doi.org/10.1007/s12310-010-9038-1

Layard, R. (2005). Therapy for All on the NHS. Sainsbury: Sainsbury Centre for Mental Health. http://www.centreformentalhealth.org.uk/pdfs/layard_lecture_scmh_120905.doc

Layard, R. (2008). Child Mental Health: Key to a Healthier Society. Sainsbury: Sainsbury Centre for Mental Health.

Layard, R., Clark, D., Knapp, M., \& Mayraz, G. (2007). Cost-Benefit Analysis of Psychological Therapy. London: The Centre for Economic Performance.

Lochman, J. E., \& Dodge, K. A. (1998). Distorted Perceptions in Dyadic Interactions of Aggressive and Nonaggressive Boys: Effects of Prior Expectations, Context and Boys’ Age. Development and Psychopathology, 10, 495-512. 
Luna, C., \& Turner, C. (2001). The Impact of the MCAS: Teachers Talk about High-Stakes Testing. English Journal, 91, 79-87. http://dx.doi.org/10.2307/821659

Miller, L. D., Short, C., Garland, J., \& Clark, S. (2010). The ABCs of CBT: Evidence-Based Approaches to Child Anxiety in Public School Settings. Journal of Counseling and Development, 88, 432-439. http://dx.doi.org/10.1002/j.1556-6678.2010.tb00043.x

Morris, G. B. (1993). A Rational-Emotive Treatment Program with Conduct Disorder and Attention-Deficit Hyperactivity Disorder Adolescents. Journal of Rational-Emotive \& Cognitive-Behavior Therapy, 11, 123-134. http://dx.doi.org/10.1007/BF01074090

National Institute for Health and Clinical Excellence (2008). Promoting Children's Social and Emotional Wellbeing in Primary Education. London: National Institute for Health and Clinical Excellence.

Peck, A., Albrecht, S., George, C., Mathur, S., Paget, M., Ryan, J. B., White, R., \& Baker, D. (2012). Reflections on the Future of Council for Children with Behavioral Disorders: A Response to Colvin, Forness, \& Nelson. Behavioral Disorders, 37, 123-125.

Pettitt, B. (2003). Effective Joint Working between Child and Adolescent Mental Health Services (CAMHS) and Schools. London: Department of Health.

Pugh, J. (2010). Cognitive Behaviour Therapy in Schools: The Role of Educational Psychology in the Dissemination of Empirically Supported Interventions. Educational Psychology in Practice, 26, 391-399. http://dx.doi.org/10.1080/02667363.2010.521312

Robins, C. J., \& Hayes, A. M. (1993). An Appraisal of Cognitive Therapy. Journal of Consulting and Clinical Psychology, 61, 205-214. http://dx.doi.org/10.1037/0022-006X.61.2.205

Robinson, T. R., Smith, S. W., \& Miller, M. D. (2002). Effect of a Cognitive-Behavioral Intervention on Responses to Anger by Middle School Students with Chronic Behavior Problems. Behavioral Disorders, 27, 256-271.

Rosenbaum, T., McMurray, N. E., \& Campbell, I. M. (1991). The Effects of Rational Emotive Education on Locus of Control, Rationality and Anxiety in Primary School Children. Australian Journal of Education, 35, 187-200. http://dx.doi.org/10.1177/000494419103500206

Sanders, T. (2003). Clearing the NCLB Hurdle. American School Board Journal, 190, 26-28.

Sapp, M. (1996). Irrational Beliefs that Can Lead to Academic Failure for African American Middle School Students Who Are Academically at Risk. Journal of Rational-Emotive \& Cognitive-Behavior Therapy, 14, 123-134. http://dx.doi.org/10.1007/BF02238186

Shannon, H. D., \& Allen, T. H. (1998). The Effectiveness of a REBT Training Program in Increasing the Performance of High School Students in Mathematics. Journal of Rational-Emotive \& Cognitive-Behavior Therapy, 16, 197-209. http://dx.doi.org/10.1023/A:1024963131417

Silverman, S., \& DiGiuseppe, R. (2001). Cognitive-Behavioral Constructs and Children’s Behavioral and Emotional Problems. Journal of Rational-Emotive \& Cognitive-Behavior Therapy, 19, 119-134. http://dx.doi.org/10.1023/A:1011183506003

Squires, G. (2002). Changing Thinking and Feeling to Change Behaviour: Cognitive Interventions. Ainsdale: Positive Behaviour Management.

Squires, G. (2010). Countering the Argument that Educational Psychologists Need Specific Training to Use Cognitive Behavioural Therapy. Emotional and Behavioural Difficulties, 15, 279-294. http://dx.doi.org/10.1080/13632752.2010.523211

Squires, G., \& Caddick, K. (2012). Using Group Cognitive Behavioural Therapy Intervention in School Settings with Pupils Who Have Externalizing Behavioural Difficulties: An Unexpected Result. Emotional and Behavioural Difficulties, 17, 25-45. http://dx.doi.org/10.1080/13632752.2012.652423

Squires, G., \& Dunsmuir, S. (2011). Embedding Cognitive Behavioural Therapy Training in Practice: Facilitators and Barriers for Trainee Educational Psychologists (TEPs). Educational Psychology in Practice, 27, 117-132. http://dx.doi.org/10.1080/02667363.2011.567089

Trip, S., Vernon, A., \& McMahon, J. (2007). Effectiveness of Rational-Emotive Education: A Quantitative Meta-Analytical Study. Journal of Cognitive \& Behavioral Psychotherapies, 7, 81-93.

US Public Health Service (2000). Report of the Surgeon General's Conference on Children's Mental Health: A National Action Agenda. Washington DC: Department of Health and Human Services.

Vernon, A. (1989a). Assessment and Treatment of Childhood Problems: Applications of Rational-Emotive Therapy. Counseling and Human Development, 22, 1-12.

Vernon, A. (1989b). Thinking, Feeling, and Behaving: An Emotional Education Curriculum for Children. Champaign, IL: 
T. Banks et al.

Research Press.

Wilde, J. (1994). The Effects of the Let’s Get Rational Board Game on Rational Thinking, Depression, and Self-Acceptance in Adolescents. Journal of Rational-Emotive \& Cognitive-Behavior Therapy, 12, 189-196. http://dx.doi.org/10.1007/BF02354596

Zionts, P., Banks, T., \& Killu, K. (2013). Teaching Disturbed and Disturbing Students: An Integrative Approach (3rd ed.). Austin: Pro-Ed. 